\title{
NEONATAL CATARACT: AETIOLOGY, PATHOGENESIS AND MANAGEMENT
}

\author{
I. C. LLOYD ${ }^{1}$, M. GOSS-SAMPSON ${ }^{2}$, B. G. JEFFREY ${ }^{1}$, A. KRISS ${ }^{1}$, \\ I. RUSSELL-EGGITT ${ }^{1}$ and D. TAYLOR ${ }^{1}$ \\ London
}

\begin{abstract}
SUMMARY
We review the epidemiology, aetiology, pathogenetic mechanisms and clinical management of neonatal cataract. Visual development and the effects of visual deprivation in the infant with congenital cataract are discussed and related to the timing of surgery. Surgical techniques and the important operative and post-operative complications are discussed. We review post-operative management and compare the different techniques available for aphakic correction, and describe the VEP changes found in patients with monocular cataract.
\end{abstract}

\section{INTRODUCTION AND EPIDEMIOLOGY}

Congenital cataract remains an important and frequently difficult problem to manage and the care of affected children is costly and time consuming. A number of studies have shown that although this condition is potentially treatable it continues to account for a significant proportion of children with partial sight and blindness. It was found to be the commonest cause of blindness among children attending the Yamanashi school for the blind in Japan $(16 / 67)^{1}$ and similarly one of the three major causes in the Royal Blind School in Edinburgh, Scotland (12/99). ${ }^{2}$ Stewart-Brown and Haslum's recent British study indicated that it was the most common cause of partial sight or blindness in a nationally representative cohort of 15,000 ten year old children. ${ }^{3}$ Congenital cataract accounted for nearly $19 \%$ of children in British Columbia who were legally blind in a study by Robinson et al. covering 29 years ${ }^{4}$ but a more recent survey of childhood blindness in the Republic of Ireland produced a much lower proportion $(8 / 172){ }^{5}$

In recent years there have been many improvements in

'Department of Ophthalmology, The Hospitals for Sick Children, Great Ormond Street.

${ }^{2}$ Division of Biochemistry and Metabolism, The Institute of Child Health, London.

Correspondence to: D. Taylor FRCS FRCP FCOphth, Department of Ophthalmology, The Hospitals for Sick Children, Great Ormond Street, London. the treatment of children with congenital cataracts. Better understanding of amblyopia, more sophisticated surgical techniques, and advances in contact lens technology have all contributed to this. Early treatment is one of the most important factors in determining the eventual visual outcome. ${ }^{6}$ Early detection is therefore vital and it is important that paediatricians and general practitioners receive adequate training in this area. ${ }^{7}$ Correct surgical management and the subsequent post-operative care are important. This includes accurate optical correction together with appropriate occlusion therapy. Parental motivation to achieve the same goals as the ophthalmic team is essential. Much time, patience and understanding is required by ophthalmologists and their co-workers involved in the management of these children.

\section{AETIOLOGY}

All children with congenital cataract should be carefully assessed in an attempt to establish a cause. This should include a history and physical examination, examination of other family members and, where indicated, appropriate laboratory studies, neurophysiological assessment and imaging techniques. It is useful to work closely with a paediatrician and clinical geneticist as this helps to reduce unnecessary investigations and thereby saves time and expense. The Flow Chart in Fig. 5 provides a schematic approach to the diagnosis and assessment of the neonate presenting with congenital cataract. The ophthalmologist is often able to identify hereditary cataracts and those that are typically developmental, i.e. in association with persistent hyperplastic primary vitreous or anterior segment dysgenesis, in an otherwise well child. Approximately half of all congenital cataracts are idiopathic, ${ }^{8}$ and in particular, a cause for unilateral cataract is rarely found. ${ }^{9}$ Hereditary cataracts are usually inherited as an autosomal dominant trait with associated microphthalmos. ${ }^{10}$ These cataracts are often lamellar in morphology. The parents and all siblings of affected children should be examined in every case as there may be very variable expressivity of the gene within the family..$^{9}$ Thus an apparently normal 
parent or sibling may have a visually insignificant sutural cataract whilst the more severely affected child has a dense nuclear cataract. X-linked inheritance may also occur and present similarly with a markedly affected male child of a mildly affected or asymptomatic mother (Figs. 1 and 2). ${ }^{11}$ Autosomal recessive inheritance is uncommon ${ }^{12}$ but should be considered particularly if there is consanguinity or multiple affected offspring with unaffected parents.

Any history of maternal febrile illness or skin rashes during pregnancy should be sought. First trimester rubella infection is a cause of severe multiple congenital anomalies and cataracts (unilateral or bilateral) may be present at birth or develop in the first year of life. ${ }^{8}$ The cataract is related to direct virus invasion of the lens and virus may be cultured from the lens matter removed at surgery up to four years of age and is probably responsible for the vigorous post-operative uveitis that often occurs in these children. ${ }^{13}$ Congenital infection with the varicella zoster virus, herpes simplex virus, toxoplasmosis and cytomegalovirus have also been associated with cataracts. ${ }^{14}$ Metabolic disorders associated with cataract formation result in failure to thrive and systemic symptoms in all except the mild disorder of galactokinase deficiency. Children with galactokinase deficiency are usually. well and cataracts are the only clinical manifestation. ${ }^{15}$ It is inherited in an autosomal recessive manner and homozygotes develop bilateral, lamellar cataracts in fetal life or early infancy. Galactokinase deficiency is common, however, therefore a careful examination of even asymptomatic parents is essential to exclude dominantly inherited cataracts in a child who is incidentally galactokinase deficient. Galactosaemia is also an autosomal recessive trait and is characterised by a deficiency of galactose-1-phosphate uridyl transferase. Tissue accumulation of galactose-1-phosphate leads to failure to thrive, lethargy and bilateral lamellar or 'oil-drop' cataracts (Fig. 3). ${ }^{16}$ Splenomegaly, hepatomegaly and jaundice and subsequent mental retardation ensue unless galactose is withheld from the diet. In

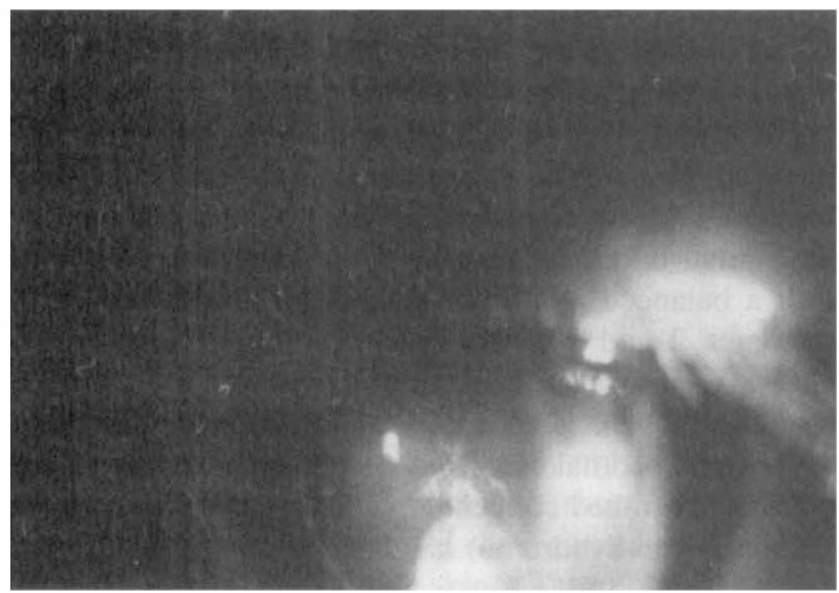

Fig. 1 some patients the cataracts may disappear when the diet is altered (Fig. 4) ${ }^{17}$ Reducing substances are present in the urine of patients with galactokinase deficiency and galactosaemia one to two hours after a galactose containing meal (milk). If this test is positive, further enzymatic assays can be used to distinguish the two disorders. Children who fail to thrive and have cataracts should have their urine screened for amino-acids. Lowe's syndrome is an $\mathrm{X}$-linked recessive condition manifested in infancy by dysmorphic facies, mental and psychomotor retardation, failure to thrive, aminoaciduria, vitamin-D resistant rickets and cataracts. ${ }^{18}$ Virtually all affected males with Lowe's syndrome have cataracts at birth and glaucoma may also be associated. The lens has a reduced anteroposterior diameter and may show developmental anomalies such as posterior lentiglobus or a discoid shape. ${ }^{19}$ The carriers of this syndrome commonly have fine peripheral dot lens opacities and so female relatives should be examined for this clinical sign. ${ }^{20}$

Hypocalcaemia in the neonate may be secondary to hypoparathyroidism or pseudohypoparathyroidism. ${ }^{8}$ Subsequent cataract formation is related to increased lens capsule permeability and the morphology of the lens opacity is usually lamellar with punctate cortical dots. Fits are often the initial symptom associated with failure to thrive. Serum calcium and phosphate levels should be checked in such children and further management of their general problems undertaken by a paediatrician. Hypoglycaemia in the perinatal period is usually characterised by fits and neurological problems. Cataracts associated with this are often transient but may persist as lamellar opacities if the hypoglycaemia is recurrent. ${ }^{10}$

Low birth weight premature infants were noted in one study to have an incidence of transient cataracts of $2.7 \% .^{21}$ These were characterised by fluid vacuoles bilaterally just anterior to the posterior lens capsule and usually underwent complete resolution over a one week to four month period. Pike $e t$ al. however feel that prematurity itself is an unlikely cause of cataract. They propose that perinatal dif-

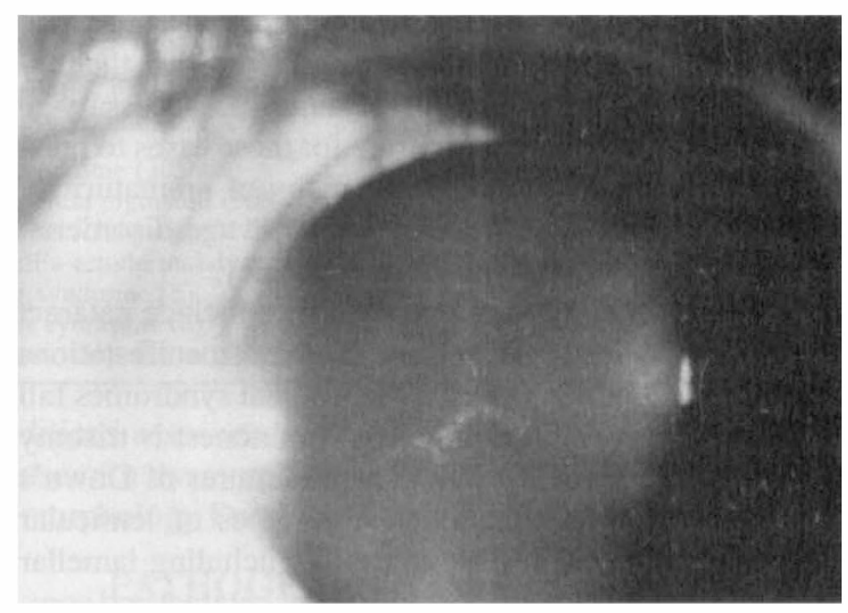

Fig. 2

Figs. 1 and 2. X-linked sutural cataracts. Figure 1 shows the right 'lazy' eye of the mother of a boy with congenital cataracts. A significant sutural and nuclear lens opacity (of which she was unaware) is present. Figure 2 shows the left eye which has a visually insignificant sutural lens opacity. 


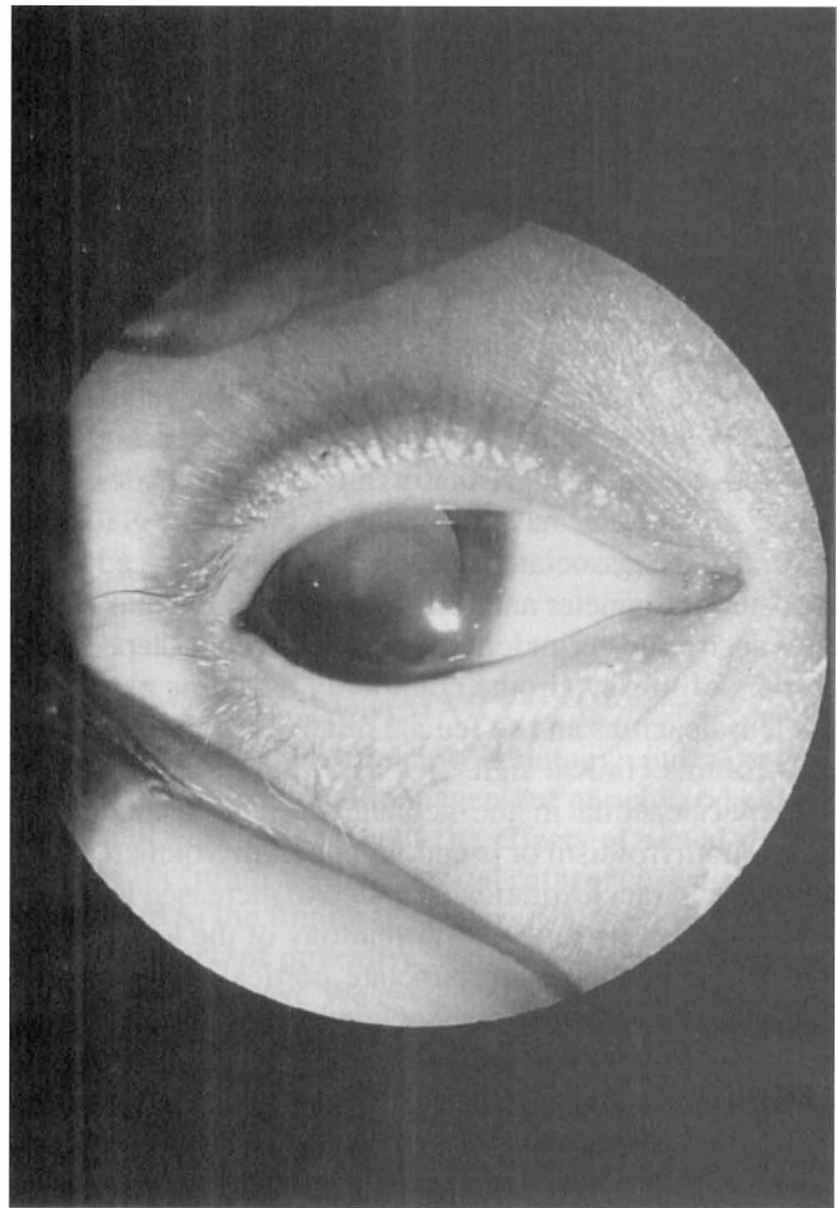

Fig. 3

ficulties are often related to preceding maternal or fetal abnormality and that this abnormality is more likely to predispose to cataract. ${ }^{22}$

Certain ocular disorders are associated with congenital cataract and they are listed in Table I(V). Infants with Persistent hyperplastic primary vitreous need careful assessment to exclude posterior vitreous and retinal involvement as in these cases the prognosis is very poor. ${ }^{23}$ Retinoblastoma should be borne in mind in any child with a unilateral cataract in whom it is difficult to clearly visualise the fundus. ${ }^{24,25}$ Ultrasound and/or CT scanning is necessary in these cases. It is however very rare for these cases to present in the neonatal period. Retinopathy of prematurity, ${ }^{24}$ aniridia $^{24}$ and the anterior chamber cleavage disorders ${ }^{26}$ are also associated with cataract in infancy.

A large number of inherited disorders include cataract in the neonatal period as one of their manifestations (Table I(VII)). A number of chromosomal syndromes fall within this group and of these the commonest is trisomy 21 (Down's syndrome). The general features of Down's syndrome are well known. ${ }^{8}$ Several types of lenticular opacities may occur in this condition including lamellar cataract, sutural cataract, posterior polar cataract and complete mature cataract. The incidence of cataracts in young children with Down's syndrome is of the order of $60 \%$ and this increases in adolescence. Trisomy $13,{ }^{8}$ Trisomy $18,{ }^{8}$ Turner syndrome ${ }^{8}$ and Cri-du-chat syndrome (deletion of

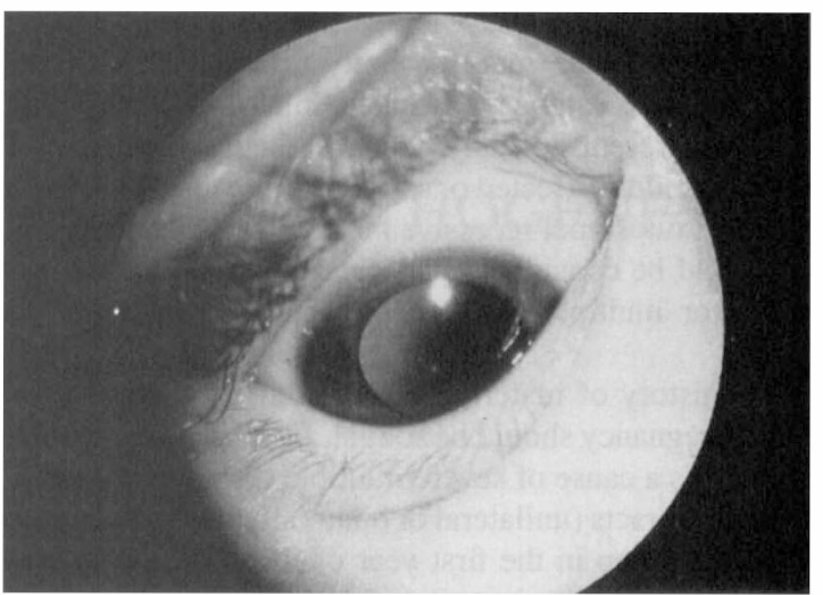

Fig. 4

Figs. 3 and 4. Galactosaemia. Figure 3 shows a typical 'oildrop' lens opacity in an infant with Galactosaemia. Figure 4 is from the same eye after the infant has had dietary restriction of galactose and shows complete regression of the lens opacity.

the short arm of chromosome 5$)^{27}$ are all associated with congenital cataract. A number of studies involving genetic mapping of families with congenital cataracts have been performed in recent years..$^{28,29,30}$ It is estimated that any of twelve different genes may cause dominantly inherited congenital cataracts but as yet only two such genes have been assigned to specific chromosomal loci. ${ }^{31}$ Linkage analysis studies have found that the gene for autosomal dominant pulverulent cataracts lies on chromosome 1 due to its close linkage to the Duffy blood group and similarly an autosomal dominant posterior polar cataract lies in a region close to the haptoglobin gene on chromosome $16{ }^{29}$ Breaks in two non-homologous chromosomes follwed by aberrant reunion is known as reciprocal translocation. Autosomal dominant anterior polar cataracts associated with a balanced reciprocal translocation between chromosomes 2 and 14 have been reported. ${ }^{28}$ Reese et al. showed reciprocal translocation between the short arms of chromosomes 3 and $4[\mathrm{t}(3 ; 4)(\mathrm{p} 26.2 ; \mathrm{p} 15)]$ in a father and son with autosomal dominant congenital cataracts. ${ }^{29}$ The locus for X-linked congenital cataracts and microcornea (Nance-Horan syndrome) has been shown to lie around Xp22.2-p22.3. ${ }^{30}$ All of these areas would be good sites for further investigations into the genetic basis of these types of cataract.

Many other inherited disorders are associated with cataract and it is essential to seek a genetic and paediatric 
Table. Aetiology of Cataract in the Neonate

\begin{tabular}{|c|c|c|}
\hline I & Idiopathic & approximately $50 \%(8)$ \\
\hline II & Intrauterine Infection & $\begin{array}{l}\text { Rubella (14) } \\
\text { CMV (14) } \\
\text { Varicella Zoster (14) } \\
\text { Herpes Simplex (14) } \\
\text { Toxoplasma (14) }\end{array}$ \\
\hline III & Metabolic Disorders & $\begin{array}{l}\text { Galactosaemia (McKusick 230400) (16) } \\
\text { Galactokinase deficiency (230350) (15) } \\
\text { Marginal Maternal Galactokinase deficiency (34) } \\
\text { Hypocalcaemia }(8,10) \\
\text { Hypoglycaemia }(10) \\
\text { Alpha-mannosidosis (248500) (34) } \\
\text { Sorbitol dehydrogenase deficiency (182500) (34) } \\
\text { Hyperglycinuria (34) } \\
\text { Sialidosis (256550) (34) }\end{array}$ \\
\hline IV & Prematurity & $(21)$ \\
\hline $\mathrm{V}$ & Ocular Disease & $\begin{array}{l}\text { PHPV (35) } \\
\text { Aniridia (10620) (24) } \\
\text { Aniridia Plus (36) } \\
\text { Retinopathy of prematurity (24) } \\
\text { Anterior chamber cleavage syndromes (26) } \\
\text { Intra-ocular tumour }(24,25)\end{array}$ \\
\hline VI & Inherited Without Systemic Abnormality & $\begin{array}{l}\text { Autosomal Dominant }(116700)(10) \\
\text { Autosomal Recessive }(212700)(11) \\
\text { X-linked Recessive }(302200)(12)\end{array}$ \\
\hline$V I I$ & Inherited With Systemic Problems & \\
\hline 1. & Chromosomal: & $\begin{array}{l}\text { Trisomy } 21(8) \\
\text { Trisomy } 13-15(8) \\
\text { Trisomy } 16-18(8) \\
\text { Turner syndrome-45 X0 (8) } \\
\text { Cri-du-chat syndrome-Deletion on chromosome } 5 \text { (27) }\end{array}$ \\
\hline 2. & Skeletal disease: & $\begin{array}{l}\text { Conradi-Hunermann syndrome (118650) (37) } \\
\text { Rhizomelic Chondrodysplasia Punctata (215100/302950) (37) } \\
\text { Stickler syndrome }(108300)(38) \\
\text { CAMFAK syndrome }(212540)(39)\end{array}$ \\
\hline 3. & Syndactyly, Polydactyly, or other digital anomalies: & $\begin{array}{l}\text { Rubenstein-Taybi syndrome (268600) (40) } \\
\text { Ellis van Creveld syndrome (225500) (41) }\end{array}$ \\
\hline 4. & Central Nervous System abnormalities: & $\begin{array}{l}\text { Marinesco-Sjogren syndrome (248800) (42) } \\
\text { Norrie's disease (310600) (43) } \\
\text { Martsolf syndrome (212720) (44) } \\
\text { Cerebro-oculo-facial-skeletal syndrome (214150) (45) } \\
\text { Smith-Lemli-Opitz syndrome (270400) (8) }\end{array}$ \\
\hline 5. & Muscle Disease: & $\begin{array}{l}\text { Myotonic dystrophy (160900) (8) } \\
\text { Cataract, lactic acidosis and cardiomyopathy (212350) (46) }\end{array}$ \\
\hline 6. & Mandibulo-facial syndromes: & $\begin{array}{l}\text { Hallermann-Streiff syndrome (234100) }(32) \\
\text { Nance-Horan cataract-dental syndrome }(302350)(30)\end{array}$ \\
\hline 7. & Renal Disease: & Lowe's syndrome $(309000)(18,19)$ \\
\hline 8. & Dermatological Disease: & $\begin{array}{l}\text { Goltz syndrome (305600) } \\
\text { Incontinentia pigmentii }(308300)(47,8) \\
\text { Congenital ichthyosis }(212400)(8) \\
\text { Marshall's ectodermal dysplasia }(8) \\
\text { Schafer syndrome (8) } \\
\text { Siemens syndrome }(8) \\
\text { Cataracts, Alopecia and Sclerodactyly }(212360)(48)\end{array}$ \\
\hline
\end{tabular}

opinion before starting treatment. Hallermann-Streiff-François syndrome may present with dense white cataracts in association with short stature, skull abnormalities, hypotrichosis, thin curved nose and a prominently veined atrophic skin. ${ }^{32}$ The clinical geneticist or dysmorphologist is most important in identifying such children and in providing accurate genetic counselling for the parents. A more complete list of causes of cataract in the neonate is listed in Table I. There are many other con- ditions associated with cataracts in case reports and the use of a dysmorphology database (e.g. the London Dysmorphology Database $)^{33}$ may be useful in diagnosis.

\section{PATHOGENESIS OF CONGENITAL CATARACT}

The pathogenic mechanisms of cataract formation in infancy and childhood are not yet fully understood, however, there has been some research on cataract associated 
CONGENITAL CATARACT

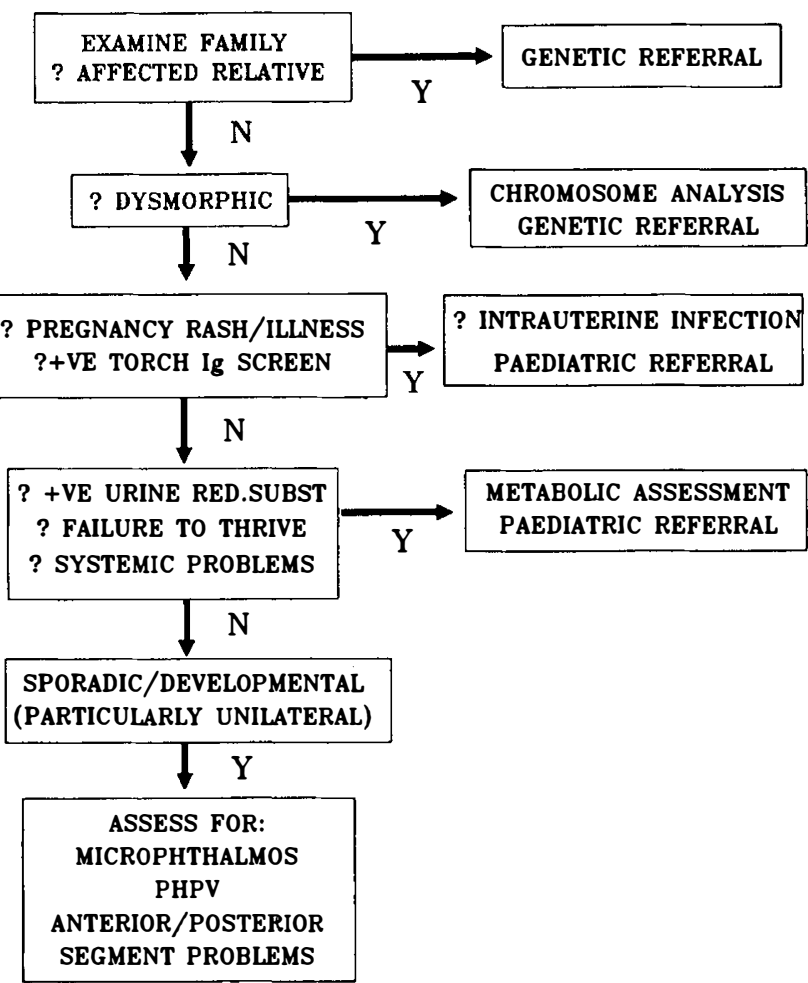

Fig. 5. Flow chart for diagnosis in congenital cataract.

with inherited metabolic disorders and, recently, oxidative damage to the lens and associated structures by oxygen derived free radicals has been implicated.

\section{Metabolic disease}

Cataracts associated with inherited metabolic disorders usually appear in infancy and early childhood since the underlying defect often causes damage to the susceptible developing lens. It is now generally accepted that defects in the metabolism of hexose sugars such as in diabetes and galactosaemia lead to osmotically induced cataracts. In untreated or poorly controlled diabetics, glucose accumulates in the aqueous humour and lens and is reduced to the impermeant polyol sorbitol via the aldose reductase pathway. Subsequent metabolism of sorbitol is very slow and results in its lenticular accumulation followed by hydration of the lens fibres with associated membrane permeability changes. This leads to electrolyte imbalance (which inhibits protein synthesis), decreased levels of reduced glutathione, ATP and amino acids. These biochemical changes are accompanied by the disintegration and vacuolation of swollen fibres which eventually leads to the formation of cortical opacities. ${ }^{49}$ This, however, is rarely seen in infant diabetics but usually becomes apparent later in life.

Osmotically induced cataracts can be observed within the first week of life in patients with galactosaemia due to galactose-1-phosphate uridyl transferase deficiency (Fig. 3) ${ }^{16}$. In the milder variant of galactosaemia in which there is an absence of the enzyme galactokinase, cataracts can be observed in the first few months of life and appear to be the only manifestation of this condition ${ }^{15}$. In these cases the aldose reductase pathway converts accumulated galactose to galactitol. The accumulation of this then leads to lens fibre swelling and opacities. Early galactose restriction in these patients (by six weeks) can prevent the progression of the cataracts and in some cases regression is observed (Fig. 4) ${ }^{17}$. In vivo studies using experimental models of cataracts due to abnormal sugar metabolism have shown that they can be alleviated or prevented by aldose reductase inhibitors ${ }^{49}$.

In infants with disorders of glycoprotein degradation such as $\alpha$-mannosidosis there is an accumulation of abnormal mannose-enriched oligosaccharides causing opacities of the posterior lens capsule which can be observed within the first few months of life ${ }^{50}$. In addition to these inherited metabolic diseases there are many others as discussed above in which cataract is associated ${ }^{34.51}$ but the underlying cataractogenic process is unknown.

\section{Oxidative damage}

In recent years oxidative damage of the lens and associated structures by oxygen derived free radicals has been implicated in the aetiology of cataract formation. Oxygenderived free radicals are highly reactive species of compounds which if unchecked can oxidise lipids, proteins and other cellular components causing changes in membrane structure and function and cell damage ${ }^{52}$. Such damage in the lens and other tissues is normally prevented by cellular antioxidant defences such as superoxide dismutase, glutathione peroxidase, vitamin $\mathrm{E}$ and ascorbate $^{53}$. The potential for generating damaging concentrations of free radicals in and around the lens is considerable. The aqueous humour surrounding the lens contains high concentrations of ascorbate but this can easily undergo auto-oxidation or in the presence of high concentrations of transition metals (ie. $\mathrm{Cu}^{2+}, \mathrm{Fe}^{2+}$ ) generate free radicals ${ }^{54,55}$. Furthermore, the lens is constantly exposed to light and absorbs light in the near UV region $(300-400 \mathrm{~nm})$ which has been shown to cause oxidative damage directly and via photosensitisers ${ }^{55,56}$.

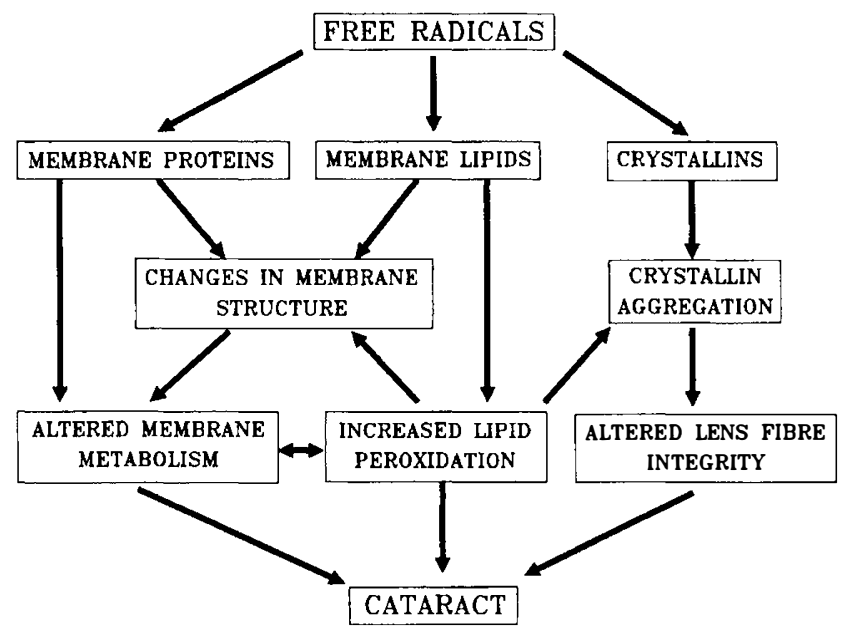

Fig. 6. Proposed sequence of events of cataract formation due to oxidative damage. 
Patients in whom oxidative damage may be an important factor in the aetiology of their cataract formation include those with Down's syndrome. There is now evidence that patients with Down's syndrome have increased indices of free radical activity and lipid peroxidation ${ }^{57}$. It has been suggested that this is due to the increased levels of $\mathrm{CuZn}$ - superoxide dismutase (carried on chromosome 21) generating increased hydrogen peroxide concentrations. In the presence of superoxide this produces highly reactive hydroxyl radicals. Infants with compromised antioxidant status and those undergoing radiation or steroid therapy may also be more susceptible to oxidative damage. The rapid evolution of some infantile cataracts may reflect more severe and readily detectable biochemical abnormalities such as increased free radical activity than those in age related cataracts.

Evidence for a role of oxidative damage in cataract formation has come from a number of in vivo and in vitro studies. Cataracts have been induced experimentally in animals by methods such as ionising radiation ${ }^{58}$, systemic methyl prednisolone ${ }^{59}$, streptozotocin diabetes ${ }^{60}$ and hyperbaric oxygen ${ }^{61}$, all of which have been shown to increase indices of free radical activity and lipid peroxidation. Treatment with antioxidants such as vitamin $\mathrm{E}^{58}$ ascorbate $^{62}$ butylated hydroxytoluene ${ }^{63}$ and carnosine ${ }^{64}$ have been shown to be effective in preventing or limiting cataract formation. In a canine model of senile cataract, where increased lipid peroxidation was demonstrated, antioxidant therapy caused partial restoration of lens transparency ${ }^{65}$. It has also been shown that the posterior subcapsular cataracts which develop in the RCS (Royal College of Surgeons) rat appear to be initiated by oxidative products of unsaturated fatty acids in the retina which leak into the vitreous and attack the posterior surface of the lens ${ }^{66}$.

Studies using lens cultures in the presence of free radical producing systems have shown cataract formation in vitro with a concomitant increase in indices of lipid peroxidation and changes in $\mathrm{K}^{+}, \mathrm{NA}^{+}$ATP ase activity. This then leads to an ionic imbalance within the lens fibres similar to those seen in osmotic sugar cataracts ${ }^{67}$. Changes in monoand divalent cation concentrations, ATP levels and water content have all been reported in lenses which contain cataracts. How lipid peroxidation initiates these changes is not yet fully understood, however it is likely that they are either due to direct oxidation of membrane proteins or oxidation of the membrane lipids which may affect membrane fluidity and protein function. Primary, secondary and end products of lipid peroxidation have all been shown to accumulate in senile cataracts ${ }^{68,69}$. Accumulation of these compounds in the lenticular epithelial membranes is a possible cause of damage preceding cataract formation. It has therefore been suggested that oxidation of membrane components is a pre-cataract state.

From the evidence the following sequence after an oxidative insult can be hypothesised (Fig. 6). Oxidation initiated at the membrane leads to peroxidation of membrane lipids and proteins with subsequent changes in membrane structure and permeability. In the presence of weakened membrane 'defences' and further lipid peroxidation, oxidative cross-linking and aggregation of the crystallins occurs resulting in lens opacity-or cataract. The exact aetiological mechanism(s) in most types of congenital cataract has yet to be delineated and much further research is needed.

\section{THE MANAGEMENT OF CONGENITAL CATARACT}

\section{The Sensitive Period, Visual Development and Prognosis}

Both unilateral and bilateral congenital cataract cause significant visual deprivation in infancy and therefore the timing of treatment is crucial to the visual development and successful rehabilitation of these children. Evidence for this has come from studies in both animals and humans. Hubel and Wiesel ${ }^{70,71}$ and von Noorden and colleagues ${ }^{72}$ conducted animal experiments in cats and monkeys respectively, and have shown that visual deprivation from birth to three months of age results in predictable developmental changes in the animals' visual system including a reduction in cortical neurons connected to the amblyopic eye as well as a reduction in cortical neurons receiving binocular input. The lateral geniculate nucleus shows a concurrent decrease in cell size in the layers innervated by the amblyopic eye. These changes result in reduced vision in the deprived eye. The age of onset and duration of visual deprivation determines the extent to which these changes occur. Correction of the visual deprivation during the sensitive period can modify these changes.

The visual systems of the different animal models are sensitive to visual deprivation for different periods, and the ages at which any resultant changes are reversible also varies. The period of reversibility or critical period, and the timing of surgery in relation to this are important factors in the prognosis for infants undergoing cataract surgery $^{6}$. The response to clinical treatment of unilateral cataract has helped to establish the duration of the critical period in humans although it is not yet fully determined. It appears to be within the first four months of life ${ }^{73}$. Drummond et $_{\text {al. }}{ }^{74}$ have shown that surgery for unilateral congenital cataract and subsequent optical correction must be performed by 17 weeks of age in order to obtain a visual acuity of 20/100 or better. Robb et al..$^{75}$ produced similar results with the poorest outcome in infants operated on after 4 months. In Gelbart and Hoyt's study of infants with bilateral congenital cataract all of those operated on after 13 weeks exhibited nystagmus and had a poor visual result $^{76}$. Only one patient out of the seven operated on after 8 weeks achieved a visual acuity better than $6 / 60$. These findings were confirmed by work from Rogers et $\mathrm{al}^{77}$.

Thus studies in both humans and animals have shown that a critical period exists in which the effects of visual deprivation upon the developing visual system are most marked and beyond which are largely irreversible. They also show that there is a longer sensitive period during 
which deprivation continues to cause changes in the developing visual system. Early surgery and detailed management of the optical correction are therefore essential and have improved the long term prognosis particularly in the bilaterally aphakic child ${ }^{76-78}$. However, visual outcome may vary markedly even in those patients whose treatment appears ideal and, in particular, in the infant with unilateral cataract ${ }^{74,75,78-84}$.

The situation in infants affected by partial cataracts, and in particular lamellar cataracts, is often more flexible and in many cases these children can be managed conservatively by close follow-up until a more complete assessment of visual function and visual behaviour can be obtained. Early surgery in some of these children can result in strabismus, amblyopia and loss of binocularity thereby counteracting the benefit of improved visual acuity. It should be noted that anterior polar cataracts do not usually result in form deprivation amblyopia but may be associated with anisometropia, whilst posteriorly located cataracts are generally more amblyogenic ${ }^{25}$.

A dense unilateral cataract in general carries a very poor visual prognosis unless surgery is performed by at least 17 weeks of life and is followed by accurate optical correction and aggressive occlusion to the contralateral eye ${ }^{74,75,78-84}$. Subsequent careful monitoring of the vision in both eyes by electrophysiological or psychophysical methods is helpful in assessing the degree of occlusion therapy required ${ }^{75,81,82}$. Difficulty in cooperation with occlusion therapy is a major factor accounting for relatively poor visual results in otherwise uncomplicated eyes. Surgical intervention may not be indicated if the parents are not committed to the visual rehabilitation of the eye and some unilateral partial cataracts may be managed by occlusion therapy of the contralateral eye alone.

It is often difficult to determine the onset of a cataract and occasionally an eye expected to be densely amblyopic will develop good vision after cataract extraction. This is due to it being a progressive infantile cataract rather than one present from birth.

\section{SURGERY}

\section{Pre-surgical Assessment}

Surgery should only be performed after careful assessment of the whole globe and in particular optic nerve and retinal function in all children with significant cataracts. Clinical tests such as fixation behaviour are helpful together with pupillary reflexes. An afferent pupil defect suggests a poorer long term prognosis due to optic nerve or retinal pathology. The posterior pole should be assessed by ophthalmoscopy and ultrasound performed if the cataract prevents an adequate view. Electroretinography, visual evoked responses and forced choice preferential looking are also extremely helpful when deciding whether surgical intervention is warranted.

Infants with visually significant bilateral cataracts should undergo surgery at the earliest opportunity without jeopardising the child's general health and our policy is to patch the first operated eye until the second eye has had surgery, to prevent amblyopia in the second operated eye ${ }^{9}$.

\section{Surgical Techniques}

Two primary techniques are currently utilised for congenital cataract surgery:

(A) Aspiration is a method originally popularised by Scheie $^{85}$ and subsequently developed by other surgeons ${ }^{86}$. The basis of this technique is that the posterior capsule is left intact at the end of the initial operation. Subsequent surgical or Yag capsulotomy is performed only if the capsule becomes opaque enough to interfere with vision. It is a safe, simple procedure with a low rate of complications. However, opacification of the posterior capsule is virtually invariable in the infant and may be extremely rapid in onset. This opacification often occurs during the critical period for visual development and thus is a powerful cause of amblyopia due both to the occlusive effect of the opacity and its prevention of accurate retinoscopy. Posterior capsule opacification is less rapid and vigorous in the older child and so this is the technique of choice only in patients after the age of 18 months. It is not indicated in the presence of other ocular abnormalities such as PHPV, iris anomalies, lens plaques, posterior lenticonus or calcified material in the lens.

The use of a horizontally mounted YAG laser avoids the necessity for surgical capsulotomy and its associated complications but does not avoid the need for a further general anaesthetic in the young child. A YAG capsulotomy may be made electively after the wound has been closed at the end of the primary procedure in some cases, particularly if the previously operated eye showed a brisk posterior capsule opacification. The YAG laser may of course be used as an outpatient procedure in the older child ${ }^{87}$.

(B) Lensectomy-vitrectomy using a closed eye vitrectomy system is the method of choice in children under 18 months of age. The whole lens is removed including both the anterior and posterior capsule and a shallow anterior vitrectomy is performed. This provides a clear visual axis for the crucial first 18 months thereby enabling easier retinoscopy and reducing the risk of amblyopia secondary to posterior capsule opacities. Secondary cataract formation following lensectomy and anterior vitrectomy can occur ${ }^{88}$ due to vigorous regrowth of residual peripheral cortex and this is more common in microphthalmic eyes ${ }^{89}$. Some surgeons perform lensectomy through a pars plana/pars plicata approach rather than the limbal approach we favour. It is claimed that this results in easier removal of peripheral cortex, less iris manipulation and less damage to the corneal endothelium $^{89}$. This approach does carry with it the risk of entry site complications, particularly in small eyes in which the pars plana is not fully developed ${ }^{90}$. There is a danger of disinsertion of the oral retina at the time of instrument insertion and as any pars plana entry site is equivalent to a penetrating injury of the posterior segment there is inevitable incarceration of basal vitreous into the wound. Thus there is a danger of post-operative tear formation at the posterior border of the vitreous base. The effect of this may not become apparent for many years since there may be a substantial latent period before retinal detachment occurs in aphakic children. 
Limbal vitreo-lensectomy cannot be assumed to be an inherently safe technique from this point of view, as the use of high suction forces and/or an inefficient vitreous cutter may cause excessive vitreous base traction. It does however avoid vitreous incarceration as long as the surgeon is scrupulous in removing vitreous tracking to the corneoscleral wounds. The use of air injected into the anterior chamber keeps the vitreous away from the entry sites and acetylcholine facilitates identification of a peaked pupil.

The limbal approach has other advantages in that the surgeon can deal with congenital anomalies such as miotic pupils, iris anomalies and anterior hyperplastic primary vitreous under direct vision ${ }^{91}$. A disadvantage of the lensectomy technique in general is the possible occurrence of cystoid macular oedema ${ }^{92}$. Relatively recent studies however have shown that the incidence of this complication appears to be $\operatorname{low}^{89,93}$.

Instruments such as intraocular scissors, intraocular diathermy and intraocular forceps may be required to deal with congenital anomalies such as thick retrolenticular membranes. Iridectomy in eyes with extensive posterior synechiae can be performed with the vitreous cutting instrument.

\section{OPERATIVE AND POST-OPERATIVE COMPLICATIONS}

More modern microsurgical techniques have reduced markedly the incidence of operative and post-operative complications in infantile cataract surgery.

Vitreous wicks to the corneoscleral wound are a not uncommon problem after lensectomy ${ }^{91}$ and can be avoided by carefully examining the pupil for peaking intraoperatively and the use of air and miochol. A vitreous wick places the eye at risk of infection and epithelial downgrowth.

Aphakic glaucoma is less common with current surgical techniques but is still seen in approximately $6 \%$ of patients ${ }^{94}$. The incidence is much increased in children with congenital rubella, chronic uveitis, PHPV and microphthalmos ${ }^{94,23}$ but can occur in other children following congenital cataract surgery and is often related to inadequate vitrectomy at the time of lensectomy. This then leads to vitreous prolapse into the anterior chamber, pupil block, synechiae formation and iris bombe.

Physical signs suggestive of glaucoma including photophobia, corneal haziness, enlarged corneal diameters, shallowing of the anterior chamber and optic disc cupping should be sought. Any evidence of these warrants measurement of the intraocular pressure, if necessary, under anaesthetic. The subequent management of aphakic glaucoma is often difficult and may involve a further vitrectomy initially. Drainage surgery may subsequently be required.

Strabismus is a problem for the majority of children after surgery for congenital cataract: France and Frank's series ${ }^{95}$ showed that $86 \%$ of such children had developed manifest strabismus following surgery. All their children with bilateral congenital cataracts were esotropic while the unilateral cases showed an equal distribution between esotropia and exotropia. This contrasts with children with acquired cataract in whom $61 \%$ developed strabismus, the majority being exotropic. Lambert et al. ${ }^{9}$ reported that approximately $2 / 3$ of patients with bilateral congenital cataracts developed strabismus but that in most cases the angle was small and squint surgery was not necessary. Surgical intervention may be necessary before contact lens fitting or glasses correction is successful as a marked abnormality of eye position can lead to constant decentration of soft contact lenses and considerable prismatic and spherical aberration in aphakic spectacle wear.

Retinal detachment is a well recognised and extremely serious post-operative complication. It may occur within months of the initial surgery, presumably related to vitreous traction during the procedure, but most occur 20 to 30 years after surgery ${ }^{90}$. The incidence of this complication is difficult to determine because of this delay. Retinal detachments in patients who have had infantile cataract surgery are often difficult to repair due to difficulty visualising the peripheral retina through miotic pupils, capsular remnants, decompensated corneas and the presence of nystagmus. In a series from Moorfields Eye Hospital ${ }^{96}$ the affected eyes were generally axially myopic and there was a very high frequency of bilateral retinal detachment in patients who had undergone bilateral cataract surgery. In two thirds of eyes vitrectomy techniques were required for adequate surgical management of the detachment.

Bacterial endophthalmitis is a rare but potentially devastating complication. Good et al. reported three cases from two centres and each showed infection by gram positive organisms ${ }^{97}$. All three had rapid onset of signs and symptoms of endophthalmitis. They point out the need for prompt aggressive attempts at diagnosis, and subsequent treatment. A careful pre-operative evaluation for the signs and symptoms of upper respiratory tract infection is suggested and that nasolacrimal obstruction is dealt with prior to cataract surgery. Pre-operative antibiotic eye drops and subconjunctival antibiotics at the end of surgery, providing gram positive and gram negative cover are recommended. Simultaneous surgery for bilateral congenital cataracts has been advocated ${ }^{98}$ in order to avoid a second general anaesthetic and allow earlier optical correction. The rare but real occurrence of endophthalmitis argues against synchronous bilateral surgery as it would place the child at risk, however slight, of bilateral intraocular infection and potential blindness.

Chronic inflammation and corneal oedema may follow surgery on children with congenital rubella syndrome ${ }^{99}$. Topical steroids and mydriatics are useful for the inflammation while the corneal oedema usually gradually clears spontaneously.

\section{POST-OPERATIVE MANAGEMENT}

The infant aphakic eye must be accurately optically corrected and in our unit we fit most infants with contact lenses which we have found to be well tolerated and 
safe $^{100}$. Contact lenses are fitted within 1 week of surgery. In bilateral cases the eyes are operated on within 2 days of each other, and the first eye is occluded until the second eye has been operated on to prevent any early visual advantage being gained. In unilateral cases no occlusion is used until the contact lens has been fitted. Daily wear soft contact lenses are used; initially high water content and later in childhood more durable low water content contact lenses. The power of the lens is decided by retinoscopy and an overcorrection of two to three dioptres is prescribed. Contact lenses with powers between twenty and thirty five dioptres are typically required during infancy. The parents are carefully instructed in lens insertion, removal and cleaning. The lenses require replacement regularly due to changes in refractive error and lens loss. Parents are given spare lenses to avoid interruptions in their use following a loss. They are instructed to remove the contact lenses and contact the department if their child's eyes become red, photophobic or develop a discharge.

In a recent series from this hospital only twelve of eighty-three patients discontinued use of their contact lenses in a three year period ${ }^{101}$. In two of the twelve there was hypoxic ulceration of the cornea whilst the remaining ten had either an excessively high lens turnover, difficulties in handling the lenses or just preferred glasses. In total forty three eyes had complications due to the use of contact lenses including bacterial conjunctivitis, lens intolerance, corneal vasularisation, corneal oedema, hypoxic ulceration and punctate keratitis. All of these problems responded to treatment and only the two with hypoxic ulceration had to cease contact lens wear. Gas permeable contact lenses often provide a better optical correction and are less frequently associated with microbial keratitis, although they are more easily lost and more difficult to fit.

Extended wear soft contact lenses may be worn for long periods of time which is helpful in preventing amblyopia in children at high risk but they are expensive and their use carries a higher incidence of microbial keratitis.

Intra-ocular lenses are advocated by some surgeons particularly in the correction of children with unilateral congenital cataracts ${ }^{102}$. Good visual acuities have been reported in some children. Problems such as severe secondary glaucoma and corneal decompensation occuring 6 to 7 years after implantation have been reported ${ }^{103}$, and other short term complications such as vigorous intraocular inflammation and hyphaema are not uncommon. There is a high risk that secondary operations will be required. A case of bilateral blinding uveitis following a secondary lens implant for unilateral cataract has been seen at this hospital. Sympathetic ophthalmia may have played a role in the pathogenesis of this uveitis ${ }^{104}$.

The eye changes in its refractive indices markedly in the first year of life and therefore an intraocular lens could not accurately correct an infant's refractive error long term ${ }^{105}$. We feel that intra-ocular lens implantation in infancy carries an unacceptable risk of long-term problems over a normal life-span. As mentioned above, some children develop contact lens intolerance particularly in the second year of life. If the patient is bilaterally aphakic, spectacles may be well tolerated despite their poorer cosmetic appearance and their inherent optical aberrations. Unilaterally aphakic children rarely tolerate spectacle correction because of image size disparity between the two eyes. Epikeratophakia is a technique in which a tissue lens shaped from donor cornea is sewn into a trephined bed in the aphakic child's cornea. This has been shown to correct $73 \%$ of children undergoing such surgery to within three dioptres of emmetropia ${ }^{106}$ and appears to be a safe and reliable procedure. Its main indication is in the child with unilateral cataract who is contact lens intolerant, but it has been combined with cataract surgery in the older child with acquired or progressive cataract ${ }^{107}$. Elsas reports however that in his series epikeratophakia did not facilitate occlusion therapy for amblyopia as expected and that visual results remain largely related to occlusion regimes and cooperation ${ }^{108}$

\section{OCCLUSION THERAPY AND AMBLYOPIA MANAGEMENT}

Good results in children with bilateral cataracts have been possible for many years. Studies have shown that if early surgery is performed and the acuity of the two eyes monitored, then careful occlusion can help to overcome any inter-ocular acuity difference as found by visual evoked potentials or preferential looking assessment ${ }^{76,109}$ Occlusion does not usually need to be very aggressive in the bilateral aphake although there may be superimposed strabismic amblyopia.

The situation is different in the unilateral aphake in whom there is a great tendency for deprivational amblyopia in the aphakic eye. Several studies ${ }^{75,78,81,82,84}$ have shown that good visual results are now possible but that aggressive occlusion of the phakic eye is necessary. Robb et al..$^{75}$ found that if occlusion was performed for less than four hours of the waking day then there was greater than one octave difference in visual acuity between the two eyes as measured by preferential looking acuity cards. One octave difference in spatial frequency between the two eyes is a strong indication of amblyopia. Lewis et $a l .{ }^{110}$ in reporting 17 cases of unilateral cataract found that only two were compliant with their regime of occlusion of the phakic eye which consisted of $50 \%$ of waking hours. In the two who were compliant the aphakic eye acuity was better than $6 / 15$ whilst in the others who were not compliant the acuity varied from $6 / 60$ to perception of light.

It would appear that full time occlusion of the phakic eye for the first week post-operatively followed by $50 \%$ of waking hours until age 6 to 7 is generally accepted as necessary for unilateral aphakes. This may be modified according to clinical findings or $\mathrm{VEP}^{76,81,111,112}$ or $\mathrm{PL}^{75,82.111}$ estimates of acuity.

\section{VEP CHANGES IN UNILATERAL CATARACT}

Occlusion therapy has been reported as significantly 
Comparison of Normal Eyes of Unilateral Cataract Patients with Controls

A.

Pattern VEP Amplitude

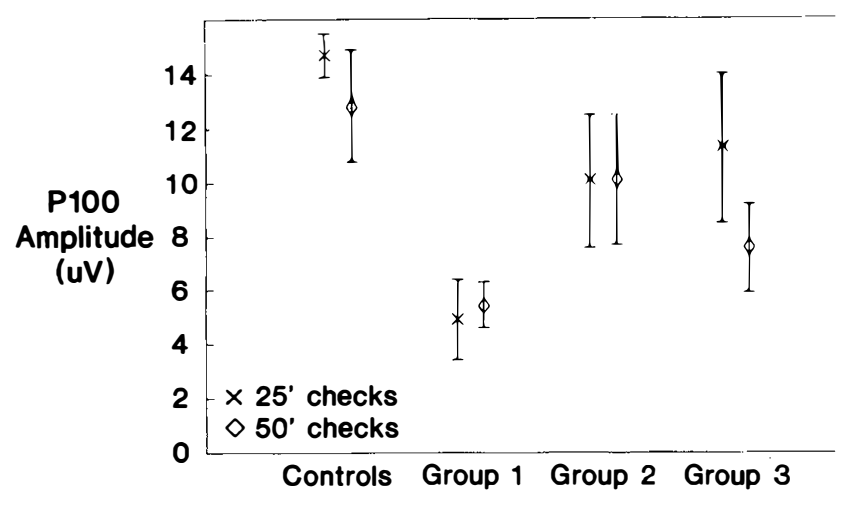

B.

Pattern VEP Latency

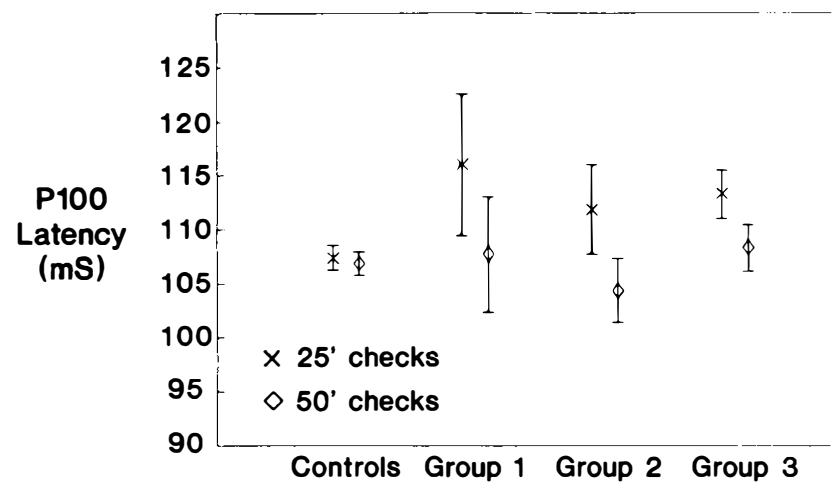

Fig. 7. Comparison of VEPs from normal eyes of unilateral cataract patients with controls. Pattern VEP amplitude and latency (25' and 50' checks) recorded from the non-affected eye of children with congenital unilateral cataract and from a group of age matched controls. Error bars indicate $95 \%$ confidence interval of standard error of the mean.

increasing VEP latency in the patched eye of unilateral amblyopes with no associated change in visual acuity ${ }^{113}$. Whilst these VEP changes were reported to have occurred as a result of patching, Leguire et al. ${ }^{114}$ reported that the contrast sensitivity function was abnormal in both eyes of children with unilateral amblyopia before occlusion therapy had started. They suggested that the amblyopic eye may negatively affect the non-amblyopic eye at a cortical level.

As part of a preliminary study in our department we examined the VEP records of 18 patients born with a unilateral cataract. One aspect of this study was to determine if VEP changes were evident in the unaffected eye of these children. Pattern VEPs provide information about the quality of spatial vision ${ }^{111}$ and we routinely record pattern VEPs for the clinical assessment of infants and children before and after surgery for congenital cataract. These clinical records were used for the preliminary study.

The most recent successful recordings of children over one year old born with unilateral cataract were examined.
The 18 patients were divided into the following groups for comparison:

Group 1: $(n=8)$ Cataract removed before 13 weeks of age

Age at test: mean $=164$ weeks, $\mathrm{SD}=90$ weeks

Group 2: $(n=6)$ Cataract removed after 9 months of age

Age at test: mean $=265$ weeks, $\mathrm{SD}=76$ weeks

Group 3: $(n=4)$ Cataract not removed because of late presentation

Age at test: mean $=193$ weeks, $\mathrm{SD}=171$ weeks

Figure 7 shows the mean pattern VEP amplitudes and latencies ( 25 and 50 minute checks) of the 'normal' eye of the three groups. Results from a group of 12 normal controls similar in age range to group 1 patients (mean $=171$ weeks, $\mathrm{SD}=82$ weeks) are also shown.

Figure 7 shows that patients who had surgery before 13 weeks old (group 1) had significantly smaller VEP amplitudes $(\mathrm{p}<0.05)$ from the phakic eye when compared with normal controls. The mean amplitudes of the other two groups while smaller than the control group are not significantly different.

Pattern VEP latencies were also measured from the phakic eye but no significant differences were noted between any of the groups and the controls.

The reduced VEPs in the phakic eye of group 1 patients were not associated with any visual acuity changes.

This preliminary study examined the clinical records of patients retrospectively and it was not possible to establish the presence/absence of latent nystagmus in the nonaffected eye of many of the patients at the time of testing. Pattern VEP amplitude for small check sizes are reduced by the presence of nystagmus ${ }^{115}$. While a large refractive error may also reduce VEPs ${ }^{116}$, none of our patients had significant refractive error at the time of VEP recording.

These results are from a preliminary study on a relatively small number of congenital unilateral cataract patients but raise some interesting questions. The average age of the children at VEP testing was over three years old and all patients who had surgery had undergone occlusion therapy. Patients who had undergone early surgery (group 1) had the smallest VEPs. These patients had undergone occlusion therapy for the longest duration and also during the critical period of visual development. Does occlusion account for these VEP changes alternatively, are reduced VEPs from the phakic eye associated with abnormal cortical interaction as suggested by Leguire? Further recordings from young children prior to any occlusion therapy should provide more insight into the effects of monocular deprivation and occlusion.

\section{REFERENCES}

1. Tsukahara S, Sasamoto M, Watanabe I, Phillips CI: Diagnostic survey at Yamanashi School for Blind: importance of heredity. Jpn J Ophthalmol 1985, 29: 315-21.

2. Phillips CI, Levy AM, Newton M, Stokoe NL: Blindness in 
schoolchildren: importance of heredity, congenital cataract, and prematurity. Br J Ophthalmol 1987, 71: 578-84.

3. Stewart-Brown SL, Halsum MN: Partial sight and blindness in children of the 1970 birth cohort at 10 years of age. J Epidemiol Community Health 1988, 42: 17-23.

4. Robinson GC, Jan JE, Kinnis C: Congenital Ocular Blindness in Children, 1945 to 1984. Am J Dis Child 1987, 141: $1321-4$.

5. Goggin $\mathbf{M}$ and O'Keefe M: Childhood Blindness in the Republic of Ireland: a national survey. $\mathrm{Br} J$ Ophthalmol 1991, 75: 425-9.

6. Taylor D, Vaegan, Morris JA, Rodgers JE, Warland J: Amblyopia in bilateral infantile and juvenile cataract. Relationship to timing of treatment. Trans Ophthalmol Soc UK 1979, 99: 170-5.

7. Rice NSC and Taylor D; Congenital cataract a cause of preventable blindness in children. $\mathrm{Br}$ Med J 1982, 285: 581-2.

8. Kohn BA: The Differential Diagnosis of Cataracts in Inf ancy and Childhood. Am J Dis Child 1976, 130: 184-92.

9. Lambert SR, Amaya L, Taylor D: Detection and treatment of Infantile Cataracts. Int Ophthalmol Clinics 1989, 29: 51-6.

10. Merin S and Crawford JS: The Etiology of Congenital Cataracts. Can J Ophthalmol 1971, 6: 178-82.

11. Krill AE, Woodbury G, Bowman JE: X-Chromosomallinked sutural cataracts. Am J Ophthalmol 1969, 68: 867-72.

12. Saebo J: An investigation into the mode of heredity of Congenital and juvenile cataracts Br J Ophthalmol 1949, 33: 601-29.

13. Cotlier E, Fox J, Smith M. Rubella virus in the cataractous lens of congenital rubella syndrome. Am J Ophthalmol 1966, 62: 233-6.

14. Lambert $\mathrm{S}$ and Hoyt $\mathrm{C}$. Ocular manifestations of intrauterine infections. In Taylor D ed. Pediatric Ophthalmology, Blackwell 1990: 91-102.

15. Gitzelmann R. Hereditary galactokinase deficiency, a newly recognised cause of juvenile cataracts. Pediatr Res 1967, 1: 14-23.

16. Segal S. Disorders of galactose metabolism. In: Scriver CR et al. eds. The metabolic basis of inherited disease, McGraw-Hill, New York 1989: 453-480.

17. Burke JP, O'Keefe M, Bowell R and Naughten ER. Ophthalmic findings in classical galactosemia-a screened population. J Ped Ophthalmol Strab 1989, 26: 165-8.

18. Johnson SS and Nevin NC. Ocular manifestations in patients and female relatives of families with the oculocerebrorenal syndrome of Lowe. Birth Defects 1976, 12: $567-72$

19. Ginsberg J, Bore KE, Fogelson MH. Pathological features of the eye in the oculocerebrorenal (Lowe) syndrome. J Ped Ophthalmol Strab 1981, 18: 16-24.

20. Cibis GW, Waeltermann JM, Whitcraft CT, Tripathi RC, Harris DJ. Lenticular opacities in carriers of Lowe's syndrome. Ophthalmol 1986, 93: 1041-6.

21. Alden ER, Kalina RE, Hodson WA: Transient cataracts in low birth weight infants. J Pediatr 1973, 82: 314-18.

22. Pike MG, Jan JE, Wong PKH. Neurological and Developmental findings in children with cataracts. Am J Dis Child 1989, 143: 706-10.

23. Karr DJ and Scott WE: Visual acuity results following treatment of persistent hyperplastic primary vitreous. Arch Ophthalmol 1986, 104: 662-7.

24. Crawford JS and Morin JD: The Lens. In Crawford JS, Morin JD eds. The eye in Childhood, Grune and Stratton 1982: 259-287.

25. Jaafar MS and Robb RM: Congenital Anterior Polar Cataract: A review of 63 cases. Ophthalmol 1984, 91: 249-52.

26. Waring GO, Rodrigues MM, Laibson PR. Anterior Chamber Cleavage Syndromes: a stepladder classification. Surv Ophthalmol 1975, 20: 3-27.
27. Farrell JW, Morgan KS, Black S. Lensectomy in an infant with cri-du-chat syndrome. J Ped Ophthalmol Strab 1988, 25: $131-4$

28. Moross T, Vaithilingham SS, Styles S, Allen Gardner H: Autosomal dominant anterior polar cataracts associated with a familial 2; 14 translocation. J Med Genetics 1984, 21: 52-3.

29. Reese PD, Tuck-Muller CM, Maumenee IH. Autosomal dominant congenital cataract associated with chromosomal translocation [t(3;4)(p26.2; 15$)]$. Arch Ophthalmol 1987, 105: $1382-4$.

30. Lewis RA, Nussbaum RL, Stambolian D. Mapping X-linked Ophthalmic Diseases: Provisional Assignment of the locus for $\mathrm{X}$-linked Congenital cataracts and microcornea (The Nance-Horan syndrome) to Xp22.2-p22.3. Ophthalmol 1990, 97: 110-20.

31. Merin S. Congenital cataracts. In Renie WA ed. Goldberg's Genetic and Metabolic Eye disease, Boston, Little Brown \& Co Inc 1986: 369-385.

32. Ronen S, Rozenmann Y, Isaacson M, Amit M, Bier N. The early management of a baby with the Hallermann-StreiffFrancois syndrome. J Ped Ophthalmol Strab 1979, 16: 119-21.

33. Winter RM, Baraitser M. London Dysmorphology Database. Oxford University Press 1990.

34. Endres W and Shin YS. Cataract and metabolic disease. $J$ Inher Metab Dis 1990 13: 509-16.

35. Pollard ZF. Treatment of Persistent Hyperplastic primary vitreous. J Ped Ophthalmol 1985, 22: 180-3.

36. Hamming NA, Miller MT, Rabb M. Unusual variant of Familial Aniridia. J Ped Ophthalmol Strab 1986, 23: 195-200.

37. Happle R. Cataracts as a marker of genetic heterogeneity in chondrodysplasia punctata. Clin Genet 1981, 19: 64-6.

38. Gellis SS, Feingold M. Sticker syndrome (hereditary arthroophthalmopathy). Am J Dis Child 1976, 130: 65-6.

39. Scott-Emuakpor AB, Heffelfinger J, Higgins JV. A syndrome of microcephaly and cataracts in four siblings? A new genetic syndrome. Am J Dis Child 1977, 131: 167-9.

40. Baraitser M, Preece MA. The Rubinstein-Taybi syndrome: occurrence in two sets of identical twins. Clin Genet 1983, 23: $318-20$.

41. Walls WL, Altman DH, Winslow OP. Chondroectodermal dysplasia (Ellis-van Creveld syndrome): report of a case and review of the literature. Am J Dis Child 1959, 98: 242-8.

42. Alter M, Talbert OR, Croffead C. Cerebellar ataxia, congenital cataracts and retarded somatic and mental maturation. Report of cases of Marinesco-Sjogren syndrome. Neurology 1962, 12: 836-47.

43. Warburg M. Norrie's disease: a new hereditary bilateral pseudotumour of the retina. Acta Ophthalmol 1961, 39: $752-72$.

44. Martsolf JT, Hunter AGW, Haworth JC. Severe mental retardation, cataracts, short stature and primary hypogonadism in two brothers. Am J Med Genet 1978, 1: 291-9.

45. Insler MS. Cerebro-oculo-facio-skeletal syndrome. Ann Ophthalmol 1987, 19: 54-5.

46. Sengers RCA, Haar BGA, Trijbels JMF, Willems JL, Daniels O, Stadhouders AM. Congenital cataract and mitochondrial myopathy of skeletal and heart muscle associated with lactic acidosis after exercise. $J$ Pediatr 1975, 86: 873-80.

47. Raab EL. Ocular lesions in Incontinentia pigmentii. J Ped Ophthalmol Strab 1983, 20: 42-8.

48. Wallis C, Saw Lan Ip F, Beighton P. Cataracts, Alopecia and Sclerodactyly: a previously apparently undescribed ectodermal dysplasia syndrome on the island of Rodrigues. $\mathrm{Am}$ J Med Genetics 1989, 32: 500-3.

49. Kador PF and Kinoshita JH. Diabetic and galactosaemic 
cataracts. In Human Cataract formation. Ciba Foundation Symposium 106. Pitman, London 1984: 48-55.

50. Kjellman B, Gamstrop I, Brun A, Ockerman PA and Palmgren B. Mannosidosis: a clinical and histopathologic study. J Pediatr 1969, 75: 366-73.

51. Michalski A, Leonard JV and Taylor DSI. The eye and inherited metabolic disease: a review. J Roy Soc Med 1988, 81: 286-90.

52. Halliwell B and Gutteridge JMC. Free radicals in biology and medicine. Clarendon Press 1989, Oxford.

53. Wayner DD, Burton GW, Ingold KU, Barclay LRC and Locke SJ. Antioxidants in human blood plasma. The relative contributions of vitamin $\mathrm{E}$, urate, ascorbate and protein to the total radical trapping antioxidant activity. Biochim Biophys Acta 1987, 925: 408.

54. Augusteyn RC. Protein modification in cataract: possible oxidative mechanisms. In: Duncan G ed. Mechanisms of Cataract Formation in the Human Lens, Academic Press, London 1981: 71-115.

55. Spector A. In Haisel H ed. The Ocular Lens. Marcel Dekker, NY 1985: 405-38.

56. Harding JJ. In Bloemendal $\mathrm{H}$ ed. Molecular and Cellular Biology of the Lens, Wiley, NY 1981: 327-65.

57. Bras A. Monteiro C and Rueff J. Oxidative stress in trisomy 21. A possible role in cataractogenesis. Ophthalmic Pediatr Genet 1989, 10: 271-7.

58. Ross WM, Creighton MO, Inch WR and Trevithick JR. Radiation cataract formation diminished by vitamin $\mathrm{E}$ in rat lenses in vitro. Exp Eye Res 1983, 36: 645-53.

59. Creighton MO, Sanwal M, Stewart-DeHaan PJ and Trevithick JR. Modelling cortical cataractogenesis. V. Exp Eye Res 1983, 37: 65-76.

60. Abraham EC, Swamy MS and Perry RE. Non-enzymic glycosylation (glycation) of lens crystallins in diabetes and aging. Prog Clin Biol Res 1989, 304: 123-39.

61. Varma SD, Chand D, Sharma YR, Kuck JF and Richards RD. Oxidative stress on lens and cataract formation: role of light and oxygen. Curr Eye Res 1984, 3; 35-57.

62. Varma SD and Richards RD. Ascorbic acid and the eye lens. Ophthalmic Res 1988, 20: 164-73.

63. Ansari NH and Srivastava SK. Allopurinol promotes and butylated hydroxy toluene prevents sugar-induced cataractogenesis. Biochem Biophys Res Commun 1990, 168: 939-43.

64. Babizhayev MA. Antioxidant activity of L-carnosine, a natural histidine-containing dipeptide in crystalline lens. Biochim Biophys Acta 1989, 1004: 363-71.

65. Boldyrev AA, Dupin AM, Bunin AY, Babizhaev AM and Severin SE. The antioxidant properties of carnosine, a natural histidine containing dipeptide. Biochem Int 1987 15: 1105-13.

66. Spector A. In: Human cataract formation. Ciba Foundation Syposium 106. Pitman, London 1984: 48-55.

67. Garner WH, Garner MH and Spector A. H202-induced uncoupling of bovine lens $\mathrm{Na}+, \mathrm{K}+-\mathrm{ATPase}$. Proc Natl Acad Sci USA 1983, 80: 2044-8.

68. Babizhayev MA. Accumulation of lipid peroxidation products in human cataracts. Acta Ophthalmol (Copenh) 1989, 67: 281-7.

69. Simonelli F, Nesti A, Pensa M, Romano L, Savastano S, Rinaldi E and Auricchio G. Lipid peroxidation and human cataractogenesis in diabetes and severe myopia. Exp Eye Res 1989, 49: 181-7.

70. Hubel DH: Exploration of the primary visual cortex, 1955-78. Nature 1982, 299: 515-24.

71. Wiesel TN: Postnatal development of the visual cortex and the influence of environment. Nature 1982, 299: 583-91.

72. Von Noorden GK and Crawford MLJ: The sensitive period. Trans Ophthalmol Soc UK 1979, 99: 442-6.

73. Vaegan and Taylor D: Critical period for deprivation amblyopia in children. Trans Ophthalmol Soc UK 1979, 99: 432-9.

74. Drummond GT, Scott WE, Keech RV: Management of monocular congenital cataracts. Arch Ophthalmol 1989, 107: 45-51.

75. Robb RM, Mayer DL, Moore BD: Results of early treatment of unilateral congenital cataracts. J Ped Ophthalmol Strab 1987, 24: 178-81.

76. Gelbart SS, Hoyt CS, Jastrebaski G, Marg E: Long term visual results in bilateral congenital cataracts. Am J Ophthalmol 1982, 93: 615-21.

77. Rogers GL, Tishler CL, Tsou BH, Hertle RW, Fellows RR: Visual acuities in inf ants with congenital cataracts operated on prior to 6 months of age. Arch Ophthalmol 1981, 99: 999-1003.

78. Parks MM: Visual results in aphakic children. Am J Ophthalmol 1982, 94: 441-9.

79. Birch EE, Stager DR, Wright WW: Grating acuity development after early surgery for congenital unilateral cataract. Arch Ophthalmol 1986, 104: 1783-7.

80. Kushner BJ: Visual results after surgery for monocular juvenile cataracts of undetermined onset. Am J Ophthalmol 1986, 102: 468-72.

81. Beller RB, Hoyt CS, Marg E, Odom JV: Good visual function after neonatal surgery for congenital monocular cataracts. Am J Ophthalmol 1981, 91: 559-65.

82. Catalano RA, Simon JW, Jenkins PL, Kandel GL: Preferential looking as a guide for amblyopia therapy in monocular infantile cataracts. J Ped Ophthalmol Strab 1987, 24: 56-63.

83. Jacobson JG, Mohindra I, Held R: Development of visual acuity in inf ants with congenital cataracts. Br J Ophthalmol 1981, 65: 727-35.

84. Cheng KP, Hiles DA, Biglan AW, Pettapiece MC: Visual Results after Early Surgical Treatment of Unilateral Congenital cataracts. Ophthalmology 1991, 98: 903-10.

85. Scheie HG. Aspiration of congenital or soft cataracts: a new technique. Am J. Ophthalmol 1960, 50: 1048.

86. Rice NSC. The surgery of cataracts in children. Proc Roy Soc Med 1976, 69: 272-4.

87. Maltzmann BA, Wagner RS, Caputo AR. Neodymium: Yag laser surgery: The treatment of Pediatric cataract disease. Ann Ophthalmol 1986, 18: 245-6.

88. Morgan KS, Karcioglu ZA. Secondary cataracts in infants after lensectomies. J Ped Ophthalmol Strab 1987, 24: 45-8.

89. Green BF, Morin JD, Brent HP. Pars plicata lensectomy/ vitrectomy for developmental cataract extraction: Surgical results. J Ped Ophthalmol Strab 1990, 27: 229-32.

90. McLeod D. Congenital cataract surgery: A Retinal surgeon's viewpoint. Aus and NZ J Ophthalmol 1986, 14: $79-84$.

91. Taylor D. Choice of Surgical Technique in the management of congenital cataract. Trans Ophthalmol Soc UK 1981, 101: 114-17.

92. Hoyt CS, Nickel AB. Aphakic cystoid macular edema: Occurrence in infants and children after transpupillary lensectomy and anterior vitrectomy. Arch Ophthalmol 1982, 100: 746-9.

93. Morgan KS, Franklin RM. Oral Fluorescein Angiography in aphakic children. J Ped Ophthalmol Strab 1984, 21: 33-6.

94. Chrousos GA, Parks MM, O’Neill JF. Incidence of chronic glaucoma, retinal detachment and secondary membrane surgery in pediatric aphakia patients. Ophthalmol 1984, 9: $1238-41$.

95. France TD and Frank JW: The association of strabismus and aphakia in children. J Ped Ophthalmol Strab 1984, 21: 223-6.

96. Jagger JD, Cooling RJ, Fison LG, Leaver PK, McLeod D. Management of retinal detachment following congenital 
cataract surgery. Trans Ophthalmol Soc UK 1983, 103: $103-7$.

97. Good WV, Hing S, Irvine AR, Hoyt CS, Taylor DSI. Postoperative Endophthalmitis in Children following Cataract surgery. J Ped Ophthalmol Strab 1990, 27: 283-4.

98. Guo S, Nelson LB, Calhoun J, Levin A. Simultaneous Surgery for Bilateral Congenital cataracts. J Ped Ophthalmol Strab 1990, 27: 23-5.

99. Taylor D. Difficulties in the management of Congenital cataract. Seminars Ophthalmol 1986, 1: 104-12.

100. Holmstrom G, Speedwell L, Taylor D. Contact lensesstill the only solution for infant aphakia. Eur J Implant Ref Surg 1990, 2: 265-7.

101. Amaya LG, Speedwell L, Taylor D. Contact lenses for infant aphakia. Br J Ophthalmol 1990, 74: 150-4.

102. BenEzra D and Paez JH. Congenital Cataract and Intraocular lenses. Am J Ophthalmol 1983, 96: 311-14.

103. BenEzra D. Intraocular lenses for Unilateral Paediatric aphakia. Early lenses and long term follow up. Eur $J$ Implant Ref Surg 1990, 2: 285-9.

104. Wilson-Holt N, Hing S, Taylor DSI. Bilateral Blinding Uveitis in a child after secondary intraocular lens implantation for unilateral Congenital cataract. J Ped Ophthalmol Strab 1991, 28: 116-18.

105. Moore BD. Changes in aphakic refraction of children with unilateral Congenital cataracts. J Ped Ophthalmol Strab 1989, 26: 290-5.

106. Morgan KS, McDonald MB, Hiles DA, Aquavella JV, Durrie DS, Hunkeler JD, Kaufman HE, Keales RH, Sanders DR. The Nationwide Study of Epikeratophakia for Aphakia in Older Children. Ophthalmol 1988, 95: 526-31.

107. Morgan KS and Somers M. Update on Epikeratophakia in Children. Int Ophthalmol Clinics 1989, 29: 37-42.
108. Elsas FJ. Visual Acuity in Monocular Pediatric Aphakia: Does Epikeratophakia Facilitate Occlusion Therapy in Children Intolerant of Contact Lens or Spectacle wear? $J$ Ped Ophthalmol Strab 1990, 27: 304-9.

109. Lorenz B and Worle J. Visual Results in Congenital Cataract with the use of contact lenses. Graefe's Arch Clin Exp Ophthalmol 1991, 229: 123-32.

110. Lewis TL, Maurer D, Brent HP. Effects on perceptual development of visual deprivation during infancy. $\mathrm{Br} J$ Ophthalmol 1986, 70: 214-20.

111. Sokol S, Hansen VC, Moskowitz A, Greenfield P, Towle VL. Evoked potential and preferential looking estimates of visual acuity in pediatric patients. Ophthalmol 1983, 90: 552-61.

112. Gottlob I, Fendick MG, Guo S, Zubcov AA, Odom JV, Reinecke RD. Visual acuity measurements by swept spatial frequency visually-evoked-cortical potentials: Clinical application in children with various visual disorders. J Ped Ophthalmol Strab 1990, 27: 40-7.

113. Arden GB, Barnard WM. Effect of occlusion on the visual evoked response in amblyopia. Trans Ophthalmol Soc UK 1979, 99: 419-26.

114. Leguire LE, Rogers GL, Bremer DL. Amblyopia: The normal eye is not normal. J Ped Ophthalmol Strab 1990, 27: $32-8$.

115. Kriss A, Gresty M, Shawkat F, Taylor D. Effects of induced nystagmus on pattern and flash VEPs. Ophthalmol Physiol Opt 1989, 9: 103-9.

116. Collins DW, Carroll WM, Black JL, Walsh M. Effect of refractive error on the visual evoked response. $\mathrm{Br}$ Med $\mathrm{J}$ 1979, 1: 231-2. 